\title{
THE CHARACTERISTICS OF POTENTIAL PASSENGERS OF AN INDONESIAN HIGH-SPEED TRAIN (CASE STUDY: JAKARTA--BANDUNG)
}

\author{
Andyka Kusuma $^{1 *}$, Nuryani Tinumbia ${ }^{2}$, Pujas Leksono Bakdirespati ${ }^{1}$ \\ ${ }^{1}$ Department of Civil Engineering, Faculty of Engineering, Universitas Indonesia, Kampus UI Depok, \\ Depok 16424, Indonesia \\ ${ }^{2}$ Civil Engineering Study Program, Faculty of Engineering, Universitas Pancasila, Serengseng Sawah, \\ Jagakarsa, South Jakarta 12640, Indonesia
}

(Received: December 2016 / Revised: June 2017 / Accepted: November 2017)

\begin{abstract}
Indonesia is one of the largest economics compared to others in the Association of Southeast Asian Nations (ASEAN), with a population of 240 million in 2016. Most of the country's economic and service-related activities are located on the island of Java, which is home to $50 \%$ of the population. A good and reliable transport infrastructure is therefore critical to ensuring that the movement of both passengers and goods is efficient, fast, reliable, and safe. The Indonesian government has initiated a High-Speed Train (HST) service to connect Jakarta and Surabaya, two big cities in the west and east of Java, respectively, in order to improve mobility and connectivity on Java. The first phase of the HST project is planned to connect Jakarta and Bandung. This study aims to understand the travel characteristics of potential HST passengers, which is important for predicting demand for the HST. The study conducts roadside interviews using a stated preference methodology for several passenger transport modes serving the Jakarta-Bandung route, namely the private car, 10-seater bus (shuttle), coach, and conventional rail. The survey asks respondents about their potential for shifting from their current transit mode to HST. The HST stations will be located in Halim (Jakarta) and Gedebage (Bandung). The study finds that most of the respondents have good economic welfare. A total of $64 \%$ of the respondents agreed that they would pay an HST ticket price of between 200,000 and 300,000 rupiahs to save 90 minutes' travel time. Furthermore, the average amount paid to use a passenger car on the same trip is 200,000 rupiahs, which is slightly higher than the amount paid by a train passenger (Rp. 150,000). This finding demonstrates that the passenger traffic vehicle capitulates the benefit of choosing HST in comparison with the existing transport modes. It should also be noted that there is greater uncertainty with regard to traffic conditions for road traffic in comparison to that faced by railway passengers. In more detail, a sensitivity analysis indicates that passengers traveling from Jakarta could be more easily shifted to the HST than could passengers traveling from Bandung. The fact that those in Jakarta indicate a greater preference to shift to a faster transport mode than those in Bandung indicates that people in Jakarta place a higher value on time. This information is also useful for operational policy, including ticket price differentiation based on travel time period and travel origin-destination.
\end{abstract}

Keywords: High Speed Train; Shifting mode; Stated preference survey; Ticketing differentiation

\footnotetext{
*Corresponding author's email: andyka.k@eng.ui.ac.id, Tel: +62-21-7270029, Fax: +62-21-7270028

Permalink/DOI: https://doi.org/10.14716/ijtech.v8i6.724
} 


\section{INTRODUCTION}

Indonesia is one of the largest economics compared to others in the Association of Southeast Asian Nations (ASEAN), with a population of 240 million in 2016. Most of the country's economic and service-related activities are located on the island of Java, which is home to 50\% of the population. A good and reliable transport infrastructure is therefore critical to ensuring that the movement of both passengers and goods is efficient, fast, reliable, and safe. The Indonesian government has initiated a High-Speed Train (HST) service connecting Jakarta and Surabaya, two big cities in the west and east of Java, respectively, in order to improve mobility and connectivity on Java (MLIT, 2008). The first phase of the HST project is planned to connect Jakarta and Bandung. This study aims to understand the travel characteristics of potential HST passengers, which is important for predicting demand for the HST.

The product in the train industry concerns the operation and service characteristics that meet passenger needs. In this case, a number of train services can be categorized based on speed, frequency, traveling time, and types of service area. It is a high-intensity activity that involves the movement of both people and goods at high speed from one location to other locations. In Indonesia, most of the country's economic, industrial, and education activities are located in Java, particularly along the North Java Sea corridor. The Indonesian government thus wants to introduce an HST to connect the two cities of Jakarta and Bandung (first phase), as part of a wider Java HST network.

This study aims to understand the travel characteristics of potential HST passengers. This includes reviewing the travel pattern characteristics of people traveling from Jakarta to Bandung or vice versa and analysing the willingness to pay and sensitivity level of these potential HST passengers due to changes in time savings and costs (Lembaga Teknologi Fakultas Teknik, 2003). The results of this study may be useful in the operation of the HST and particularly for determining fare strategy.

\section{LITERATURE REVIEW}

\subsection{High-speed Train}

An HST is a train that operates at speeds of between 250 and $350 \mathrm{kph}$ and runs on a special track in order to reduce traveling time and maintain the level of service (European Union, 1996; Fröidh, 2008; Chen \& Hall, 2011). HST services have been introduced by many countries, including the TGV (France), ICE (Germany), AVE (Spain), Shinkansen (Japan), and CRH (China). HSTs in Europe serve both domestic and international routes, i.e., London (UK)-Paris (France) via the Channel Tunnel, and Paris-Brussels (Belgium) (Arduin \& Ni, 2005). Meanwhile, HSTs in Asian countries (Japan and China) serve domestic routes that connect their respective capital cities with other cities (Givoni, 2006). This is similar to the situation in Indonesia, whereby the train connects Jakarta with several other metropolitan areas on the island of Java, including Bandung, Cirebon, Semarang, and Surabaya. Note, however, that only the Jakarta-Bandung section of the proposed network will be constructed in the first phase.

The stakeholder needs to consider the travel time, level of comfort, and accessibility in order to define the optimum price (Avineri \& Bovy, 2008; Barus et al., 2016). The train will take approximately 50 minutes from Jakarta (Halim) to Bandung (Gedebage), with two intermediate stops in Karawang and Walini. The train service will compete with several existing transport modes on this link, namely the private car, 10-seater bus (shuttle), coach, and conventional rail. Having good accessibility is an advantage for the railway modes, with train stations in many cities located around the city center and connecting with other public transport modes such as buses and commuter trains (LEMTEK UI, 2016). The stations for the Jakarta-Bandung line will be located in Halim (east part of Jakarta) and Gedebage (south part of Bandung) due to space 
issues. The stakeholder is therefore required to provide reliable public transport that connects those stations with the city center, with the above-mentioned characteristics affecting the attractiveness of the train and the demand forecast analysis.

\subsection{Discrete Choice Model}

Demand forecasting in a transportation system is a critical element. It aims to capture the behavior of consumers to evaluate transportation services and facilities (Ben-Akiva \& Lerman, 1985; Ortuzar \& Willumsen, 2011). This study forecasts potential demand for the JakartaBandung HST. Discrete choice applications in the field of transportation research capture the individual's choice of transport mode for a particular condition. In the early stage, the model was focused on the value of time analysis, with a trade-off between travel time and cost. The value indicates a monetary value for the travel time savings for the assumed transport mode choice, whether this is a binary or multiple choices.

The logit model is one of the statistical tools that can be used and applies a system of forecasting with an adequate level of detail (Ben-Akiva \& Lerman, 1985; Fröidh, 2008). The model represents the preferences of each individual in the decision-making process. He/she may prefer a choice with the highest utility in comparison to the other (transport mode) choices. The utility function allows for the inclusion of different variables that represent the decision-making process, i.e., pricing, travel time, frequency, and sociodemographic information. The inclusion of sociodemographic information assists the model to capture individuals' travel behavior for different categories, i.e. gender, age, and income.

The utility function implies an individual's preference for choosing a particular transport mode. In this case, the decision regarding transport choice is represented as a transport mode utility function. Each individual would prefer to shift to a transport mode that provides the highest utility compared to the whole set of available transport modes. Moreover, several attributes may affect the systematic part of mode choice utility $\left(U_{n}^{l}\right)$. The function is thus written based on the preference, as follows:

$$
U_{n}^{L}(t)=\beta^{I} X_{n}^{L}(t)+\varepsilon_{n}^{I}(t) \quad l \in\left\{i_{i} j\right\}
$$

where; $X_{n}^{l}(t)$ is vector of explanatory variables associated with individual $n$ for alternative mode at hypothetical condition $t ; \beta^{l}$ is vector of estimated parameters associated with mode $l$; $\varepsilon_{n}^{l}(t)$ is random error term associated with mode $l$ of driver $n$ at hypothetical condition $t ; i, j$ is the observed transport modes.

The choice in this paper is binary, whereby each individual has the choice of precisely two alternatives. This paper observes the choice of individuals to either stay or shift from the current modes to HST with respect to the perception of a better traveling environment. This situation is considered as a binary choice model. The choice of model assumes that the random error term $\varepsilon_{n}^{l}$ is independent and identically distributed (IID). This assumption for the random error term produces transit choice as a binary logit model.

The binary logit model assumes that $\varepsilon_{n}=\varepsilon_{n}^{l}-\varepsilon_{n}^{L}$ is logistically distributed. In this case, the distribution of $\varepsilon_{n}$ is skewed to the left side. Therefore, the probability of choosing transport mode $l$ is written as follows:

$$
P\left(l_{n}(t)\right)=\frac{1}{1+e^{-\mu \boldsymbol{\beta}^{r}\left(\boldsymbol{x}_{n}^{i}-\boldsymbol{X}_{n}^{j}\right)}}
$$

where; $P\left(l_{n}(t)\right)$ is the probability of individual $n$ choosing specific transport mode $l$ at time $t$ 
The choice of transport mode $l$ indicates the passenger's individual choice between the current mode or shifting to the HST between Jakarta and Bandung. There is no shift required if the individual is satisfied with their current transport mode. In this case, the individual remains with his/her current transport mode. As shown in Figure 1, the individual is required to make a choice between maintaining his current mode (i.e., private car, 10-seater bus (shuttle), coach, and conventional rail). If the driver of a private car chooses his/her current mode, then no mode shifting is required. If the individual selects the HST, which provides higher utility (fare, shorter travel time, accessibility), then mode shifting occurs.

\section{METHODOLOGY}

The model is built based on stated preference survey data. The modeling in this study uses the binomial logit approach by comparing the HST with the existing transport modes separately. The division of the model is shown in Figure 1.
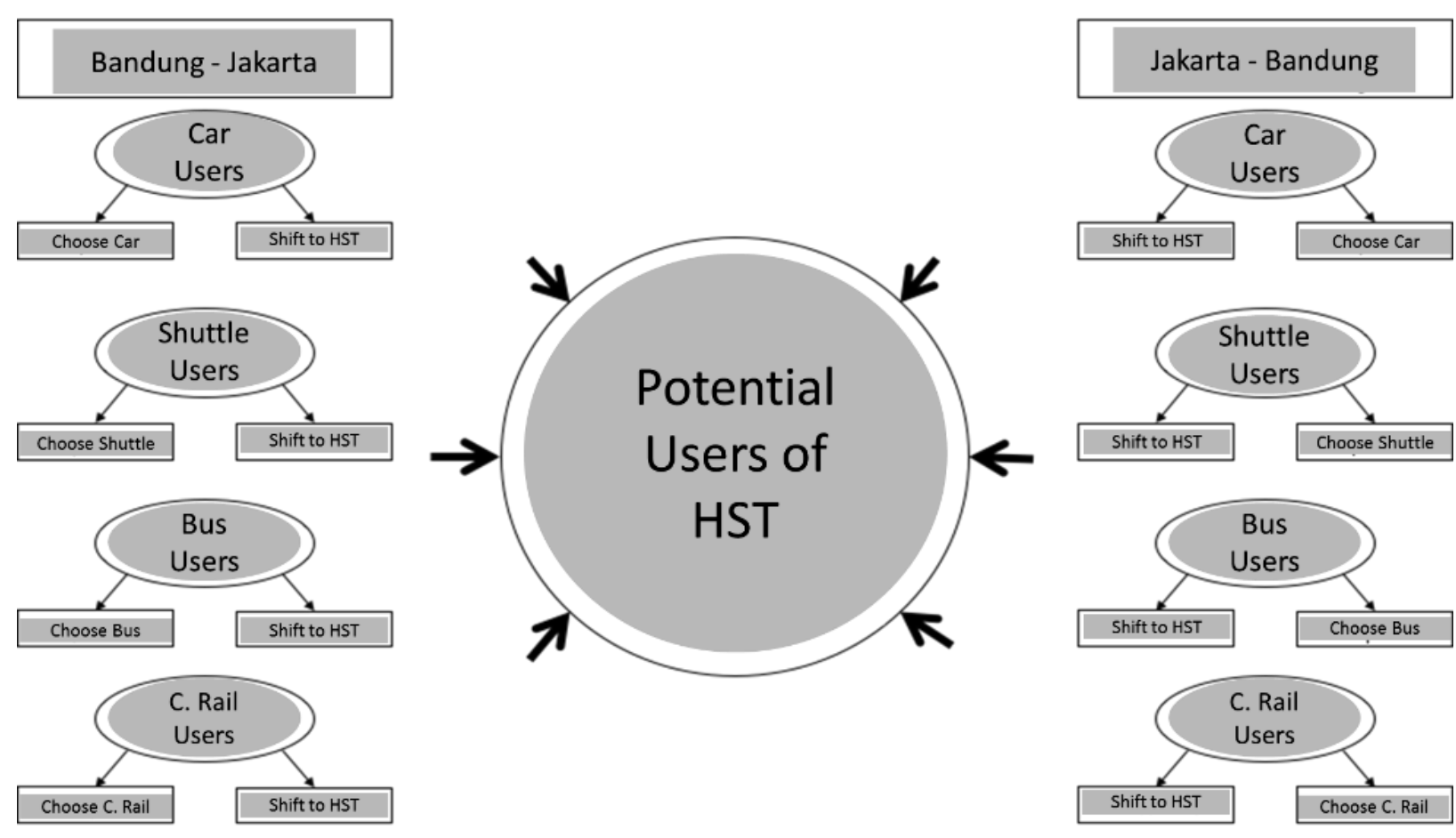

Figure 1 Division of the model

In a binomial logit model, as also described by Ortuzar and Willumsen (2011), the probability of alternative $i$ being chosen by individual $\mathrm{n}$ is expressed in Equation 1.

$$
P(i)=\frac{\exp \left(U_{i}\right)}{\sum \exp \left(U_{i}+U_{j}\right)}
$$

And the probability of choosing alternative $j$ is given as:

$$
P(j)=1-P(i)=\frac{1}{1+\exp \left(U_{i}-U_{j}\right)}
$$

The probability of an individual choosing alternative $i$ is a function of the difference utilities between the two alternatives. Assuming that the function is linear, then the difference in utility 
is expressed in the form of utility difference in the number of relevant $n$-attributes between the two modes (Equation 3).

$$
U_{i}=\beta_{0}+\beta_{1} X_{1}+\beta_{2} X_{2} \ldots \beta_{n} X_{n}
$$

where $U_{i}$ is the utility of $i$-choice; $X_{i} \ldots X_{n}$ is the product attributes; $\beta_{1} \ldots \beta_{n}$ is the coefficient of attributes; and $\beta_{0}$ is the constant models.

This study focuses on measured components such as travel costs and travel time that were deemed to be significant to the individual's choice of mode. In addition, in terms of time, time delays and time accessibility from an HST station to the city center were also included within the respondents' consideration when choosing a mode. These attributes were described to the respondents via stated preference survey.

The utility equation in this study uses a combination of total travel time plus the time delay (TOTTDEL) and travel costs (COST). Individuals will choose and shift to HST when the utility value of HST is greater than the utility value of the alternative/existing modes (AM). The utility equation can be given as the following Equation 6.

$$
U_{(H S T-A M)}=\beta_{0}+\beta_{1}\left(T_{O T T D E L_{H S T}}-\text { TOTTDEL }_{A M}\right)+\beta_{2}\left(\operatorname{COST}_{H S T}-\operatorname{COST}_{A M}\right)
$$

Limdep software (NLOGIT 5) is used as a tool in building a modal choice model (binomial logit) between HST-private car, HST-shuttle, HST-bus, and HST-conventional rail.

\section{ESTIMATION RESULTS}

The utility function model was built based on the difference utilities of each competing mode among HST-private car, HST-shuttle, HST-bus, and HST-conventional rail. The output statistics of each model are shown in Table 1.

\begin{tabular}{|c|c|c|c|c|c|c|c|c|c|}
\hline \multirow{2}{*}{ No. } & \multirow{2}{*}{ Variables } & \multicolumn{4}{|c|}{ HST - $\quad$ Private car } & \multicolumn{4}{|c|}{ HST - Shuttle } \\
\hline & & Coefficients & t-stat & P-value & t-table & Coefficients & t-stat & P-value & t-table \\
\hline & Constant & 0.28329 & 1.34 & 0.181 & \multirow{3}{*}{1.9611} & 1.45656 & 3.01 & 0.0026 & \multirow{3}{*}{1.9667} \\
\hline 1 & Travel time & -0.00382 & -3.4 & 7E-04 & & -0.00423 & -1.61 & 0.1063 & \\
\hline 2 & Travel cost & -0.000012577 & -11.36 & 0 & & -0.000013322 & -5.7 & 0 & \\
\hline \multirow{2}{*}{ No. } & \multirow{2}{*}{ Variables } & \multicolumn{4}{|c|}{ HST - Bus } & \multicolumn{4}{|c|}{ HST - Conventional rail } \\
\hline & & Coefficients & t-stat & P-value & t-table & Coefficients & t-stat & P-value & t-table \\
\hline & Constant & 1.63668 & 4.33 & 0 & \multirow{3}{*}{1.9646} & 3.92068 & 6.98 & 0 & \multirow{3}{*}{1.9649} \\
\hline 1 & Travel time & -0.00359 & -1.72 & 0.086 & & -0.0046 & -1.4 & 0.1613 & \\
\hline & Travel cost & -0.000015202 & -11.18 & 0 & & -0.000034127 & -11.82 & 0 & \\
\hline
\end{tabular}

Table 1 General model statistics

Based on Table 1, most of the coefficients of variables have an influence on the model. The alternative specific constant (ASC) for all models has a positive value. In other words, the respondents would tend to prefer using HST as opposed to sticking with their current modes. Statistically, the travel cost attributes for all competition modes affect the individual's choice of mode. In reality, however, the travel time attributes for HST-shuttle, HST-bus, and HSTconventional rail have less of an influence on the modal choice of each individual.

Next, modeling for Bandung-Jakarta and Jakarta-Bandung is carried out separately to capture the specific characteristics of travel between both cities. The travel time and travel cost 
attributes for HST-private car are found to be very influential on the models. In contrast to the other modes, both attributes have less influence statistically on the modal choice of individuals. Yet in reality, both attributes strongly affect the individual in making decisions.

A summary of the models is given in Table 2. In general, there is some information to be drawn from the estimation model. The travel cost attribute (COST) has a negative sign (-) for all models of the utility function, as expected. As the difference in travel cost between HST and existing modes increases, so the utility will be reduced, thus reducing the probability of choosing HST and increasing the probability of an individual choosing the existing modes.

Table 2 Summary of models

\begin{tabular}{|c|c|}
\hline \multicolumn{2}{|r|}{ General Models } \\
\hline HST-Car & $\mathrm{U}_{\mathrm{HST}-\mathrm{Car}}=0.28329-0.00382 \times\left(\mathrm{TOTTDEL}_{\mathrm{HST}}-\mathrm{TOTTDEL}_{\mathrm{Car}}\right)-0.000013 \times\left(\mathrm{COST}_{\mathrm{HST}}-\mathrm{COST}_{\mathrm{Car}}\right)$ \\
\hline HST-Shu & $\mathrm{U}_{\text {HST-Shu }}=1.45656-0.00423 \times\left(\right.$ TOTTDEL $\left._{\mathrm{HST}}-\mathrm{TOTTDEL}_{\mathrm{Shu}}\right)-0.000013 \times\left(\mathrm{COST}_{\mathrm{HST}}-\mathrm{COST}_{\mathrm{Shu}}\right)$ \\
\hline HST-Bu & $\mathrm{U}_{\mathrm{HST}-\mathrm{Bu}}=1.63668-0.00359 \times\left(\right.$ TOTTDEL $\left._{\mathrm{HST}}-\mathrm{TOTTDEL}_{\mathrm{Bu}}\right)-0.000015 \times\left(\mathrm{COST}_{\mathrm{HST}}-\mathrm{COST}_{\mathrm{Bu}}\right)$ \\
\hline HST-CR & $\mathrm{U}_{\mathrm{HST}-\mathrm{CR}}=3.92068-0.0046 \times\left(\right.$ TOTTDEL $\left._{\mathrm{HST}}-\mathrm{TOTTDEL}_{\mathrm{CR}}\right)-0.000034 \times\left(\mathrm{COST}_{\mathrm{HST}}-\mathrm{COST}_{\mathrm{CR}}\right)$ \\
\hline \multicolumn{2}{|r|}{ Bandung-Jakarta Models } \\
\hline HST-Car & $\mathrm{U}_{\mathrm{HST}-\mathrm{Car}}=0.14722-0.00387 \times\left(\right.$ TOTTDEL $\left._{\mathrm{HST}}-\mathrm{TOTTDEL}_{\mathrm{Car}}\right)-0.000015 \times\left(\mathrm{COST}_{\mathrm{HST}}-\mathrm{COST}_{\mathrm{Car}}\right)$ \\
\hline HST-Shu & $\mathrm{U}_{\text {HST-Shu }}=2.51109-0.00188 \times\left(\right.$ TOTTDEL $\left._{\mathrm{HST}}-\mathrm{TOTTDEL}_{\mathrm{Shu}}\right)-0.000016 \times\left(\mathrm{COST}_{\mathrm{HST}}-\mathrm{COST}_{\mathrm{Shu}}\right)$ \\
\hline $\mathrm{HST}-\mathrm{Bu}$ & $\mathrm{U}_{\mathrm{HST}-\mathrm{Bu}}=2.01867-0.0063 \times\left(\right.$ TOTTDEL $\left._{\mathrm{HST}}-\mathrm{TOTTDEL}_{\mathrm{Bu}}\right)-0.000017 \times\left(\mathrm{COST}_{\mathrm{HST}}-\mathrm{COST}_{\mathrm{Bu}}\right)$ \\
\hline HST-CR & $\mathrm{U}_{\mathrm{HST}-\mathrm{CR}}=4.86352-0.00691 \times\left(\mathrm{TOTTDEL}_{\mathrm{HST}}-\mathrm{TOTTDEL}_{\mathrm{CR}}\right)-0.000042 \times\left(\mathrm{COST}_{\mathrm{HST}}-\mathrm{COST}_{\mathrm{CR}}\right)$ \\
\hline \multicolumn{2}{|r|}{ Jakarta-Bandung Models } \\
\hline HST-Car & $\mathrm{U}_{\mathrm{HST}-\mathrm{Car}}=0.41581-0.00388 \times\left(\right.$ TOTTDEL $\left._{\mathrm{HST}}-\mathrm{TOTTDEL}_{\mathrm{Car}}\right)-0.000011 \times\left(\mathrm{COST}_{\mathrm{HST}}-\mathrm{COST}_{\mathrm{Car}}\right)$ \\
\hline HST-Shu & $\mathrm{U}_{\mathrm{HST}-\mathrm{Shu}}=0.40625-0.0064 \times\left(\mathrm{TOTTDEL}_{\mathrm{HST}}-\mathrm{TOTTDEL}_{\mathrm{Shu}}\right)-0.000011 \times\left(\mathrm{COST}_{\mathrm{HST}}-\mathrm{COST}_{\mathrm{Shu}}\right)$ \\
\hline HST-Bu & $\mathrm{U}_{\mathrm{HST}-\mathrm{Bu}}=1.45944-0.002 \times\left(\mathrm{TOTTDEL}_{\mathrm{HST}}-\mathrm{TOTTDEL}_{\mathrm{Bu}}\right)-0.000015 \times\left(\mathrm{COST}_{\mathrm{HST}}-\mathrm{COST}_{\mathrm{Bu}}\right)$ \\
\hline HST-CR & $\mathrm{U}_{\mathrm{HST}-\mathrm{CR}}=3.19271-0.00251 \times\left(\mathrm{TOTTDEL}_{\mathrm{HST}}-\mathrm{TOTTDEL}_{\mathrm{CR}}\right)-0.000029 \times\left(\mathrm{COST}_{\mathrm{HST}}-\mathrm{COST}_{\mathrm{CR}}\right)$ \\
\hline
\end{tabular}

Meanwhile, for the travel time attribute (TOTTDEL), if the difference in traveling time between HST and the existing modes increases (travel time of the existing modes is quicker than HST), then the utility will be reduced, thus decreasing the probability of choosing HST and increasing the probability of choosing the existing modes. The same is seen for the travel cost attribute, and the travel time attribute also has a negative sign (-) in all models of utility function, thus indicating that the travel time attribute in the utility function is appropriate to the reality. Conventional rail users will be more interested in using HST than users of the other existing modes, as seen in the constant models, where HST-conventional rail model is the greatest (3.92068).

Figure 2 illustrates the difference in utility values between HST and existing modes. The probability of each individual choosing each mode is $50 \%$, while the difference in the utility values between HST and the other modes equals zero (0). This finding confirms that there would be strong competition between the private car and HST. Meanwhile, less competition appears between HST and other modes with respect to equal travel costs and fixed travel time difference, as shown in Figure 3.

Figure 1 Figure 3 shows the probability of mode choice with respect to various differences in fares. The negative value of fare difference indicates that the cost of using HST is slightly less compared to the other modes. Meanwhile, the positive value indicates the opposite. The lines in the graph (Figure 3) tend to slope toward negative values, thus illustrating that the higher the HST fare, the lower the probability of choosing HST. 

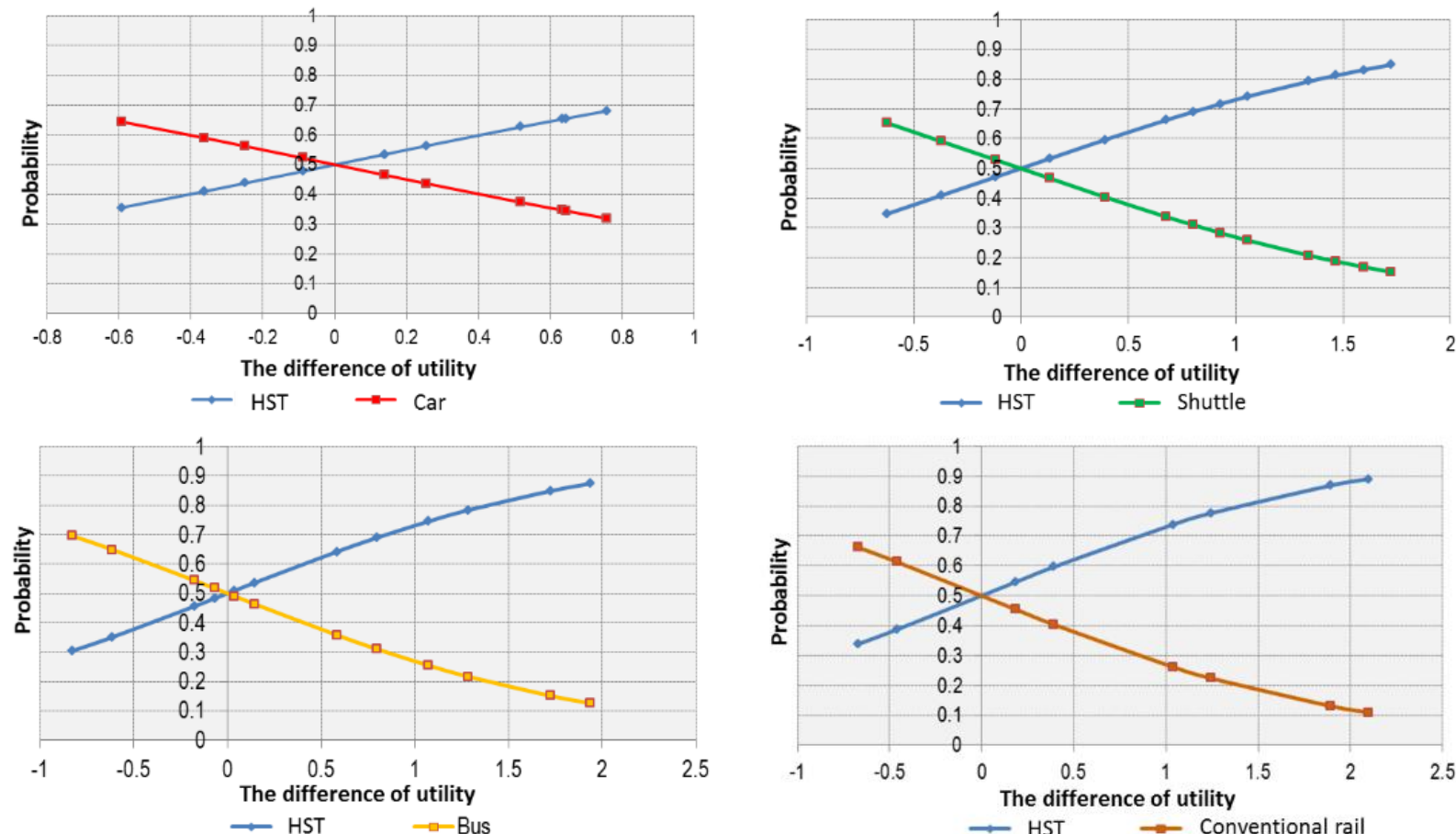

Figure 2 Modal choice curves for HST-private car, HST-shuttle, HST-bus, and HST-conventional rail

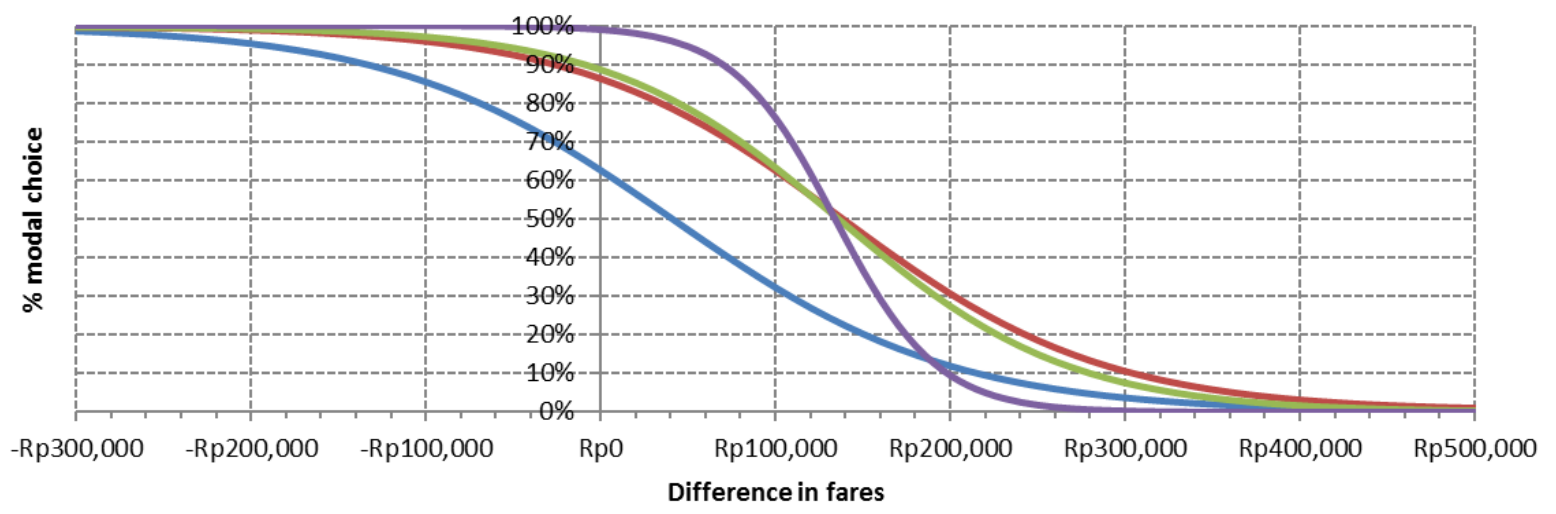

HST-Car $\longrightarrow$ HST-Shuttle HST-Bus HST-Conventional Rail

Figure 3 The sensitivity of the model due to changes in travel costs

The steep slope of the line for HST-conventional rail in the graph indicates that a small change in the fares in the model would lead to a significant change in the probability of modal choice. The study finds that the probability of a private car user choosing HST is $50 \%$, while the HST fare is more expensive; approximately 40,000 rupiahs (private cars) versus 130,000 rupiahs (shuttle, bus and conventional rail).

The two figures above confirm that the level sensitivity for choosing HST varies between transport modes. The model shows that conventional train passengers are less sensitive to shifting to HST services compared to the other existing transport modes. In this case, the stakeholder requires the development of an attractive tariff scheme to attract potential demand from the other modes. 


\subsection{Demand Analysis}

The HST fare is assumed to be 250,000 rupiahs, which refers to the earlier study of KCIC 2015, wherein the cost was 210,000 rupiahs (16 USD). The difference of 40,000 rupiahs can be viewed as the cost of using public transport to access downtown Bandung and Jakarta. The planned HST in both cities will be connected using rail-based public transport, Light Rail Transit (LRT).

The probability of shifting modes for both directions (Jakarta-Bandung and Bandung-Jakarta) assumes that the HST fare is 250,000 rupiahs. The analysis shows that the largest shift in mode occurs for conventional rail users of the Bandung-Jakarta trip (81.02\%). It is almost the same for the Jakarta-Bandung trip, whereby the largest shift in mode is also seen for conventional rail users $(62.81 \%)$. Elsewhere, the smallest shift in mode occurs for private car users, in particular for cars with more than one passenger, $23.97 \%$ for the Bandung-Jakarta trip and $11.45 \%$ for Jakarta-Bandung.

Furthermore, this study analyses the probability of shifting modes based on trip aims. For business trips, conventional rail users $(84.52 \%)$, shuttle users $(72.09 \%)$, and bus users $(58.35 \%)$ from Bandung to Jakarta will potentially shift to HST. Meanwhile, there is a slight difference with regard to the opposite origin-destination (Jakarta-Bandung), with conventional rail users $(60.81 \%)$, shuttle users $(45.40 \%)$, and cars with one passenger $(42.57 \%)$ potentially shifting to HST. For non-business trips, meanwhile, travelers from Jakarta to Bandung on existing modes will potentially shift to HST, and this trip offers more potential for acquiring passengers than does the Bandung-Jakarta trip. Passengers on the Jakarta-Bandung trip are less sensitive to ticket fare, while the opposite is true for Bandung-Jakarta. This finding is similar to that of previous research by Barus et al. (2016). Moreover, car users with more than one passenger are less interested in using HST since traveling in a large group by car is still easier and cheaper than using HST, although there is the added uncertainty of travel time due to the unpredictability of traffic conditions.

With a fare of 250,000 rupiahs, the total forecast daily passengers for HST stands at 32,474. This comprises 20,959 passengers per day for Jakarta-Bandung and 11,515 passengers per day for Bandung-Jakarta. Significant differences in the level of demand were seen in the responses given by the respondents. This may reflect differences in user preferences for the existing modes for both trips that are caused by several factors. These include the purpose of the trip, traffic conditions, the other available modes of transportation service, and fare options on the Bandung-Jakarta route that discourage travelers from choosing HST. By knowing the demand difference for the Bandung-Jakarta and Jakarta-Bandung trips, these findings may be used to aid in the development of a pricing strategy similar to how this function is performed in the world aviation industry or for rail travel in the UK.

\section{CONCLUSION}

The study finds that most of the respondents have good economic welfare. A total of $64 \%$ of the respondents agreed that they would pay an HST ticket price of between 200,000 and 300,000 rupiahs to save 90 minutes' travel time. Furthermore, the average amount paid to use a passenger car on the same trip is 200,000 rupiahs, which is slightly higher than the amount paid by a train passenger (Rp. 150,000).

The results of the modeling show that conventional rail users would be more interested in shifting to HST than those currently using the other existing modes. Furthermore, according to the fare sensitivity calculations, travelers from Bandung are more sensitive to fare price than those from Jakarta. 
The demand forecasting results for HST are based on the probability of passengers shifting mode. Demand is forecast as a total of 32,474 passengers per day; 20,959 passengers per day for Jakarta-Bandung, and 11,515 passengers per day for Bandung-Jakarta. This shows that travelers on the Bandung-Jakarta route are more price-elastic than travelers on the JakartaBandung trip. However, the estimation models are yet to be validated in any microsimulation tool. It will be interesting to test the transferability of the estimation results as an impedance in a four-step model, for the mode choice phase in particular.

These findings are based on analysis for both business and non-business trips, and there is scope for differentiating fares according to time, both during peak and off-peak periods. This highlights the strategic importance of pricing as it is carried out within both the world aviation industry and for rail services abroad. The implementation of fare differentiation can increase both demand and revenue in line with the economic concept of maximizing consumer surplus.

\section{ACKNOWLEDGEMENT}

The data used in this paper has previously been presented in the Transport survey for the Jakarta-Bandung HST Study, which was funded by PricewaterhouseCoopers (PwC).

\section{REFERENCES}

Arduin, J.-P., Ni, J., 2005. 40 Years of High-speed Railways French TGV Network Development. Japan Railway \& Transport Review, pp. 22-28

Avineri, E., Bovy, P., 2008. Identification of Parameters for a Prospect Theory Model for Travel Choice Analysis. Transportation Research Record, Volume 2082, pp. 0-16

Barus, L.S., Martell-Flores, H., Hadiwardoyo, S.P., Batoz, J.-L., 2016. Intercity Mode Choice Modelling: Considering the Intercity Transport Systems with Application to the JakartaBandung Corridor. International Journal of Technology, Volume 7(4), pp. 581-591

Ben-Akiva, M., Lerman, S.R., 1985. Discrete Choice Analysis: Theory and Application to Travel Demand, Cambridge, Massachusetts, USA.: MIT Press

Chen, C.-L., Hall, P., 2011. The impacts of High-speed Trains on British Economic Geography: A Study of the UK's InterCity 125/225 and its Effects. Journal of Transport Geography, Volume 19(4), pp. 689-704

European Union, 1996. Council Directive - on the Interoperability of the Trans-European High-speed Rail System 96/48/EC, EU

Fröidh, O., 2008. Perspectives for a Future High-speed Train in the Swedish Domestic Travel Market. Journal of Transport Geography, Volume 16(4), pp. 268-277

Givoni, M., 2006. Development and Impact of the Modern High- speed Train: A Review. Transport Reviews, Volume 26(5), pp. 593-611

Lembaga Teknologi Fakultas Teknik, 2003. Transport Survey for Jakarta-Bandung High Speed Train, Jakarta

LEMTEK UI, 2016. Transport Survey for Jakarta-Bandung High Speed Train, Jakarta

MLIT, 2008. Feasibility Study for the High-speed Train between Jakarta and Bandung, Ministry of Land, Infrastructure, Transport, and Tourism, Japan

Ortuzar, J. de D., Willumsen, L.G., 2011. Modelling Transport $4^{\text {th }}$ ed., John Wiley \& Sons, Inc 